\title{
BMJ Global Health Longitudinal path analysis of depressive symptoms and functioning among women of child-rearing age in postconflict Timor-Leste
}

Derrick Silove, ${ }^{1}$ Mohammed Mohsin, ${ }^{1,2}$ Louis Klein (1) , ${ }^{1,2}$ Natalino De Jesus Tam, ${ }^{1,3}$ Mark Dadds, ${ }^{4}$ Valsamma Eapen, ${ }^{1,2}$ Wietse A Tol, ${ }^{5}$ Zelia da Costa, ${ }^{1,3}$ Elisa Savio, ${ }^{1,3}$ Rina Soares, ${ }^{1,3}$ Zachary Steel, ${ }^{1,6}$ Susan J Rees ${ }^{1,2}$

To cite: Silove D, Mohsin M, Klein L, et al. Longitudinal path analysis of depressive symptoms and functioning among women of child-rearing age in postconflict TimorLeste. BMJ Global Health 2020;5:e002039. doi:10.1136/ bmjgh-2019-002039

Handling editor Seye Abimbola

- Additional material is published online only. To view please visit the journal online (http://dx.doi.org/10.1136/ bmjgh-2019-002039).

Received 3 October 2019 Revised 11 February 2020 Accepted 7 March 2020
Check for updates

(c) Author(s) (or their employer(s)) 2020. Re-use permitted under CC BY-NC. No commercial re-use. See rights and permissions. Published by BMJ.

For numbered affiliations see end of article.

Correspondence to

Dr Susan J Rees;

s.j.rees@unsw.edu.au

\section{ABSTRACT}

This longitudinal study indicates that exposure to the traumas of mass conflict and subsequent depressive symptoms play an important role in pathways leading to functional impairment in the postconflict period among women of child-rearing age. Our study, conducted in Timor-Leste, involved an analytic sample of 1292 women recruited at antenatal clinics in the capital and its surrounding districts. Women were re-interviewed at home 2 years later (77.3\% retention). We applied the Edinburgh Postnatal Depression Scale, the Harvard Trauma Questionnaire for conflict-related traumatic events, the WHO Violence Against Women Instrument covering the past year for intimate partner violence and the WHO Disability Assessment Schedule (WHODAS V.2.0) to assess functional impairment. A longitudinal path analysis tested direct and indirect relationships involving past conflict-related trauma exposure, depressive symptoms measured over the two time points and functional impairment at follow-up. The prevalence of predefined clinically significant depressive symptoms diminished from $19.3 \%$ to $12.8 \%$. Nevertheless, there was a tendency for depressive symptoms to persist over time $(\beta=0.20 ; p<0.001)$. Follow-up depressive symptoms were associated with functional impairment $(\beta=0.35 ; p<0.001)$. Reported conflict-related trauma occurring a minimum of 6 years earlier $(\beta=0.23 ; p<0.001)$ and past-year physical intimate partner violence $(\beta=0.26$; $p<0.001$ ) were each associated with depressive symptoms at baseline and at follow-up. A measure of poverty specific to the context and reported health problems in the mother and infant also contributed to depressive symptoms. The findings highlight the association between ongoing trauma-related depressive symptoms and the capacity of women in the childbearing age to function in multiple areas of their lives in a postconflict country. Recognition of these relationships is important in the formulation and implementation of contemporary international recovery and development policies applied to postconflict countries.

\section{INTRODUCTION}

International policies on socioeconomic development give emphasis to the importance

\section{Summary box}

What is already known?

- Exposure to violence has been established as a major contributor to symptoms of common mental disorders in general populations.

- Women have been shown to suffer higher risk of depressive symptoms than their male counterparts particularly women raising children.

- Depressive symptoms can be associated with high levels of functional impairment.

What are the new findings?

- Women in the childbearing age exposed to past mass conflict are at risk of ongoing depressive symptoms in the postconflict period.

- Recent exposure to intimate partner violence adds to the burden of depressive symptoms among these women, as does poverty and ill health in the mother and infant.

- Women with persisting depressive symptoms are more functionally impaired in multiple areas of their lives.

What do the new findings imply?

- By detecting and intervening early, agencies involved in providing mental health services in lowresource conflict-affected settings may be able to avert risk of functional impairment among women in the childbearing period.

- Identifying families in which intimate partner violence is ongoing and implementing strategies to overcome the problem may contribute to reducing depressive symptoms and increase functioning among women in the childbearing age in conflictaffected countries

of curtailing gender-based violence and promoting the participation of women in society. ${ }^{2}{ }^{2}$ Less attention has been given, however, to the role of psychological trauma and its impact on mental health as factors 
limiting the participation of women in society, particularly in low-resource postconflict countries. ${ }^{34}$

We focus on depressive symptoms because of extensive evidence that this form of emotional reaction is especially disabling in both sexes. ${ }^{5}$ Indeed, depressive disorders make a leading and growing contribution to the global burden of all diseases. While women universally experience higher rates of depression than men, this trend is amplified for women in low-resource settings. ${ }^{6}$ Moreover, the perinatal period extending into early child-rearing constitutes a high risk period for depression among women in all societies. ${ }^{7}$ Whereas there has been extensive research into both the biological and psychosocial factors that contribute to risk of maternal depression in this period of vulnerability, ${ }^{8}$ it is only very recently that emphasis has been given to the roles of past and ongoing trauma exposure, including intimate partner violence. Relatively little attention has been given to the specific context of trauma as it pertains to women in low-resource postconflict societies, and the impact that these experiences may have on depression. Similarly, there has been little recognition for the way that depressive symptoms impede women's participation in society, and in the wider field of recovery and development following mass conflict.

Several factors may contribute to risk of depressive symptoms among women in the childbearing age in lowresource conflict-affected countries. Importantly these include past exposure to the traumas of mass conflict and ongoing experiences of intimate partner violence (IPV). However, recent evidence has shown that poverty and poor general health are major contributors to depression, particularly for pregnant women and young mothers. ${ }^{9}$ As yet, however, there is a lack of epidemiological research using rigorous longitudinal designs that demonstrate a relationship between ongoing trauma-related depressive symptoms and impairments in functioning among women in the childbearing age. This is despite the high risks women face in being exposed to violence and abuse during contemporary forms of mass conflict and to IPV in the aftermath. ${ }^{10-12}$ In general, data from multiple sources indicate that repeated exposure to violence of various types-whether related to mass conflict or domestic abuse and IPV-represents a potent risk factor for the onset and persistence of common mental health symptoms including depression. ${ }^{11-13}$

The focus of our research is on depressive symptoms and functioning among Timorese women exposed to extensive trauma during the prolonged period of the Indonesian invasion and occupation (1975-1999) (see online supplementary file). Women in the present study were adolescents or young adults during two episodes of mass violence, both affecting the geographical area around the capital Dili. These periods included the humanitarian emergency of 1998-1999 when a vote in favour of independence was followed by widespread acts of retribution enacted by Indonesian-supported militia who destroyed much of the built infrastructure of the country and forcibly displaced virtually the entire population; and the period of civil conflict (2006-2007) following an attempt to assassinate the president and prime minister of the country, an upheaval that occurred 6 years prior to the baseline assessment of our study. An additional factor is that up to one-third of women in Timor-Leste have been exposed to the trauma of IPV. ${ }^{1415}$ A cross-sectional analysis of the baseline data from the present study suggested that the combination of past exposure to conflict-related trauma and more recent IPV may be particularly pathogenic in generating high levels of depressive symptoms in Timorese women. ${ }^{14}{ }^{16}$ However, the cross-sectional nature of the study precluded drawing causal inferences regarding the nature of these relationships.

In our longitudinal study, we applied a systematic approach to recruiting women from antenatal clinics in the capital, Dili, and surrounding districts of TimorLeste; with follow-ups at home, 2 years later. We draw on these data to apply longitudinal path analysis examining the role of ongoing depressive symptoms to functional impairment using a multidimensional measure of the latter construct; the relationship of past conflict-related trauma and more recent IPV with depressive symptoms; and the contribution to the model of other contextually relevant contributory factors of poverty and poor general health in the mother and infant.

\section{METHODS}

\section{Study design and participants}

The Desenvolvimentu Isin-d'iak Labarik no Inan (DILI, development and well-being of children and mothers) study conducted between June 2013 and August 2015 included a consecutive sample of women registering at the four large public antenatal clinics in the Dili District of Timor-Leste. The details of the methodology have been published previously. ${ }^{17}$ Over $90 \%$ of pregnant women use these clinics in a district comprising one-fifth of the country's population of 1.1 million. The recruitment sequence is presented as a flow chart in figure 1 .

Of 1740 women eligible at baseline, 1672 were interviewed $(96.1 \%$ response rate; see flow chart, figure 1$)$; after initial registration at the clinic, contact was lost with 66 of the 68 eligible women in the busy clinic environment, and two declined to participate. To be eligible for this study, women were in their second trimester of pregnancy as this is the most common time of registration at clinics; women manifesting signs of overt psychosis, profound intellectual impairment, or who experienced severe medical illnesses requiring referral to hospital, were excluded from this study.

Two years later, women were re-interviewed at their homes, yielding 1303 participants $(77.9 \%$ of the baseline sample) (see figure 1 for details). Attrition was mainly due to loss of contact despite five attempts to locate each woman. A minority (14) had moved to distant parts of Timor-Leste or declined to participate further (8). The 


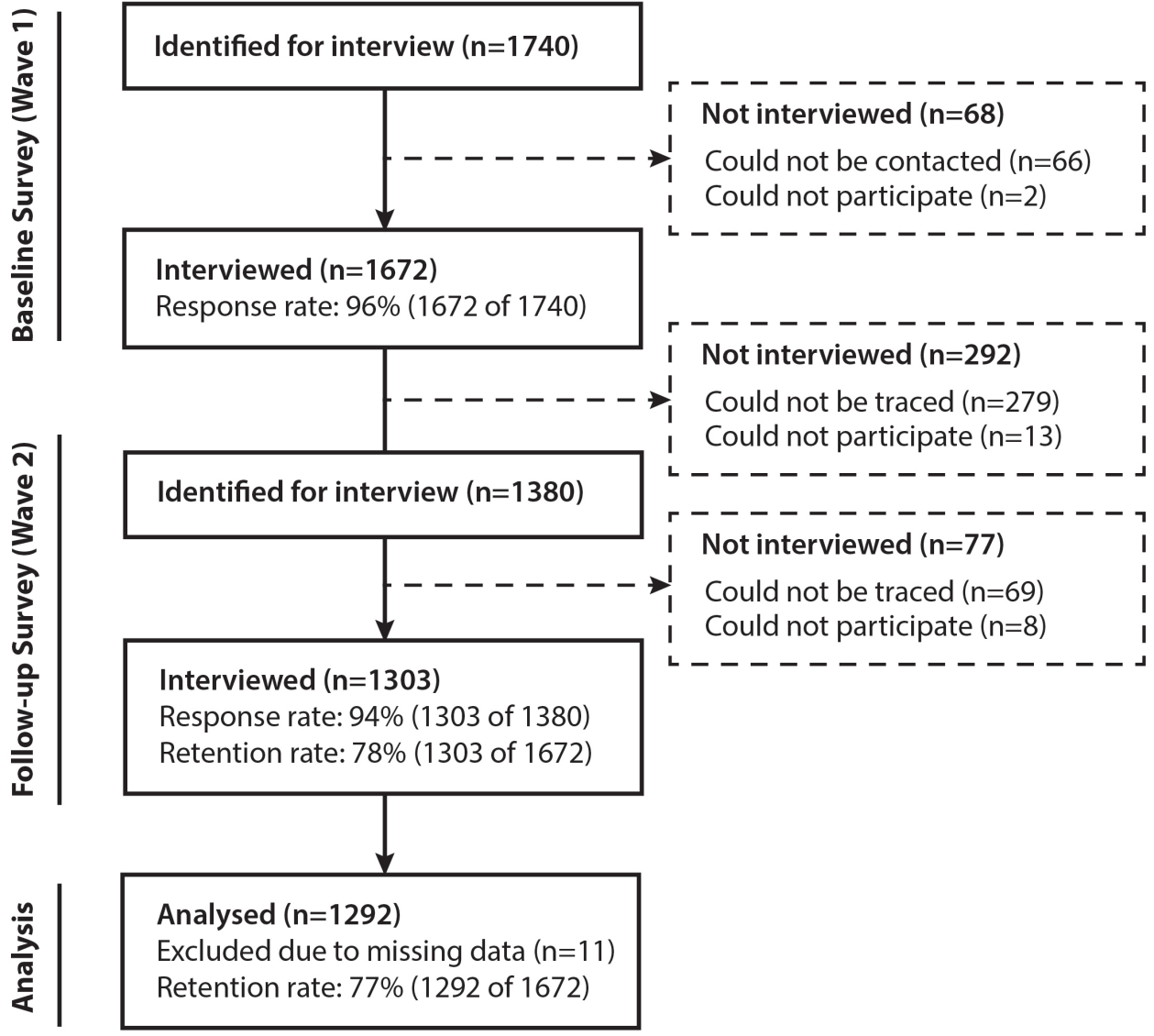

Figure 1 Participant retention and response flow chart for the two-wave survey.

final analytic sample with complete data comprised 1292 women.

\section{Participant and public involvement}

Key members of the team had worked in Timor-Leste over the preceding decade in assisting the government in mental health policy and service development. ${ }^{18} 19$ The team was based in the Alola Foundation, the peak women's not-for-profit agency in Timor-Leste. Extensive consultations and discussions had occurred with the Ministry of Health and other key government agencies; with women's groups and community leaders through the Alola foundation and with personnel in the participating clinics in the process of formulating and designing the study. During extensive piloting of interviews, feedback was sought from participants regarding the content, format and practical implementation of interviews, with a specific focus on inquiring into time constraints and risk of duress caused by any aspects of the process. The protocol was adjusted according to this feedback. Any women identified as experiencing depressive symptoms were referred to appropriate psychosocial agencies for support though few elected to seek assistance. In order to avoid biasing future assessments, routine results of each wave were not provided to participating women unless they freely requested this information, no case of which occurred.

\section{Survey measures}

All measures were repeated at both time points with the addition of the index of maternal and child health at the second assessment. Details of the cultural adaptation and translation and back-translation process have been provided previously. ${ }^{20}$

\section{Socio-demographic characteristics}

National census items were adopted to assess place of usual residence, age, marital status, level of education and employment status.

\section{Depressive symptoms}

We used the culturally adapted Edinburgh Postnatal Depression Scale (EPDS) comprising 10 items scored on a four-point self-rated Likert scale (range 0-30). ${ }^{21}$ The international threshold score of 13 or greater (addition of item scores) is applied to indicate clinically relevant depressive symptoms. For the path analysis, we used the mean EPDS symptom score. In our preliminary statistical analysis of the present data, we found a high correlation between scores on the EPDS and a measure of post-traumatic stress disorder (PTSD) consistent with past observations in the literature; to avoid the problems associated with multicollinearity, we retained the EPDS measures given that depression has previously been most consistently associated with functional impairment-the key focus of this paper-both in general populations 
and among women in the childbearing and early childrearing period. ${ }^{22}$

\section{Conflict-related traumatic events}

The 23-item traumatic event (TE) exposure list of the Harvard Trauma Questionnaire (HTQ) previously adapted to Timor-Leste ${ }^{23}$ measured experiences of political imprisonment, assault, torture, witnessing murder, exposure to atrocities, traumatic losses/separations of family or close others and deprivation of medical care for self or others in situations of severe illness. In the adaptation of the measure for previous research in Timor-Leste, we found consistency in reporting whether a listed event (eg, exposure to atrocities) had occurred. In contrast, reliability was low when participants were asked to specify when the event(s) had occurred and the number of exposures to each category of trauma; a finding consistent with our past experience working with communities in which numeracy is low. In keeping with past research in the field, we therefore use the index of lifetime exposure for each event (scored as ever exposed=1; never exposed $=0$ ). Consistent with extensive past research in the field using the HTQ, scores for each event are added to generate a lifetime TE count. ${ }^{12}$ Given that no episodes of civil conflict occurred following baseline assessment, we applied the TE count at first assessments only.

\section{Past-year intimate partner violence}

We assessed IPV at both time points using the WHO Violence Against Women Instrument (see online supplementary file) covering experiences of abuse in the past year. ${ }^{24}$ Sexual assault items were removed based on cultural sensitivities regarding inquiries into these experiences in Timor-Leste. Drawing on an earlier examination of the baseline data, ${ }^{14}$ we derived three hierarchically ordered IPV categories: (1) no IPV or low respect/ regard without severe psychological or physical abuse; (2) severe psychological abuse with or without features of category 1 but no physical abuse and (3) physical abuse with or without features of category 1 or 2 . Category 1 acted as the reference group in relevant analyses.

\section{Other putative risk factors}

Timor-Leste has a distinctive history in which a large portion of the population has been exposed to prolonged or fluctuating economic hardship arising from both climatic issues (ie, long periods of drought often followed by flooding) and repeated episodes of mass conflict and displacement. In addition, women and especially husbands (many of whom accompanied their wives to the clinics) were noted in piloting and in past studies to be highly sensitive to revealing extreme poverty for fear that their economic hardship would be seen to reflect on their capacity to provide for their family. We therefore made certain to avoid any possible attribution of responsibility in developing a context-sensitive brief measure of economic duress comprising inquiries into education level, employment status and concrete aspects of economic hardship, such as difficulties in earning enough to feed children. In preliminary examination of baseline data, the distributions of scores indicated a cutoff allowing us to assign families to dichotomous categories of no/low poverty ( 0$)$ and high poverty (1).

By endorsing symptom lists (each rated 1 , if endorsed) used by government agencies in Timor-Leste to record common manifestations of physical illness, women provided an indication of the state of health of themselves and their index child at follow-up. We addressed the pattern of skewness in the distribution of composite scores by assigning a score of 1 if any common symptom of physical illness was reported, and 0 if there were no symptoms.

\section{Functional impairment}

The WHO Disability Assessment Schedule (WHODAS V.2.0, 12-item version) has been extensively used across cultures (including in pregnancy) and comprises six core functions relating to cognition/communication, going out (mobility), self-care, interpersonal interactions, life activities (at work or home) and participation in society. ${ }^{25}{ }^{26}$ Ratings for each item range from no impairment $=1$ to extreme impairment $=5$ (total score range $12-48$ in the present sample). ${ }^{25} 26$

\section{Field team}

The field team of 18 Timorese women were selected from the community after advertising and word of mouth publicity, based on their levels of education (ie, at least some high-school attendance; capacity to read and write), past experience working on research or development projects or in helping/health agencies, and basic technical skills (eg, use of electronic devices). They received 2 weeks of training followed by 2 months of direct field experience in conducting pilot interviews, supervised by the Australian team. Pairs of interviewers were required to achieve $100 \%$ inter-rater reliability with supervisors in five consecutive assessments using the EPDS. Over the course of the study, the field team received regular supervision, feedback and ongoing in-service training. The core team has remained remarkably stable over the course of the study with very few resigning, although some have taken periods of maternity leave.

\section{Ethics}

Signed or witnessed verbal consent was obtained from all participants and interviews were conducted under conditions of strict privacy.

\section{Statistical analyses}

We provide descriptive data for all indices in tabular form. For the EPDS, we provide both the prevalence of above threshold scores (based on the international cutoff score of 13 or greater) and the mean and SD for the summary symptom score, the index used in the path analysis. Bivariate analyses were applied to examine associations between theoretically relevant explanatory variables (socio-demographic factors, TEs, IPV, poverty, maternal and child ill health) and depressive symptoms, applying 
the $\chi^{2}$ test. Indices that were statistically significant $(<0.05)$ were entered into a path model based entirely on observed variables and including direct and indirect paths. ${ }^{27} 28$ The model was constructed based on theoretical considerations and in a chronological sequence consistent with testing the key hypotheses. To avoid excessive complexity in presenting the model diagram, nonsignificant paths are not shown. The model was designed specifically to test the following paths: (1) from baseline depressive symptoms to follow-up depressive symptoms; (2) from depressive symptoms to functional impairment; (3) from trauma-related indices (conflict-related TEs and IPV) to depressive symptoms and functional impairment and (4) from poverty and maternal and child health status to depressive symptoms and functional impairment. The only exogenous index to be included in the model was age given that this variable showed a bivariate association with the depressive score in the preliminary analysis.

We assessed model fit according to a suite of conventional criteria including a non-significant $\chi^{2}$ test; the Comparative Fit Index $(\mathrm{CFI})>0.90$; the Tucker Lewis Index (TLI) $>0.90$; the root mean square error of approximation (RMSEA) $<0.08$ and the standardised root mean square residual $($ SRMR $)<0.08$. SPSS V.25 was used to generate the descriptive statistics and conduct the bivariate analyses; the path analysis was conducted in MPLUS V.7.1. ${ }^{29} 30$

\section{RESULTS}

\section{Descriptive data}

The mean age of women increased from 26.3 (SD 5.1) to 28.4 (SD 5.3) years in keeping with the 2-year timeframe between baseline and follow-up interviews. Changes were minimal in relation to marital status, education, employment and poverty levels among participating women over the 2-year time frame (table 1). The mean number of lifetime TEs reported was 5.4 (SD 3.4); the number of women who experienced IPV physical abuse increased from $322(24.9 \%)$ to $498(38.6 \%)$ over time (McNemar's test, $\mathrm{p}<0.001)$. At follow-up, 1 in 10 women $(\mathrm{n}=136$, $10.5 \%$ ) reported at least one symptom of ill health and the corresponding maternal-reported number for index children was $193(14.9 \%)$.

Depressive symptoms and functional impairment

One in five women at baseline $(n=249,19.3 \%)$ exceeded the conventional EPDS threshold for depressive symptoms while approximately one in eight $(n=163,12.6 \%)$ met that criterion at follow-up (McNemar's test, $\mathrm{p}<0.001$ ). A fifth of women reporting threshold depressive symptoms at baseline (58 out of $249,22.3 \%$ ) continued to manifest the same level of symptoms at follow-up suggesting a persisting or recurring pattern of depressive symptoms over 2 years. This subgroup represented $4.5 \%$ (58 out of 1292) or 1 in 20 women from the whole sample. In spite of the decline in depressive symptoms over time, there remained a significant correlation between baseline and follow-up mean depressive symptoms (baseline: mean=8.5, $\mathrm{SD}=4.4$; follow-up: mean $=6.4, \mathrm{SD}=4.8 ; \mathrm{r}=0.27$; paired t-test, $\mathrm{p}<0.001)$. Functioning improved over time (baseline: mean WHODAS score $=20.3, \mathrm{SD}=4.7$; follow-up: mean=16.2, $\mathrm{SD}=4.1$; paired t-test, $\mathrm{p}<0.001)$.

\section{Bivariate analyses}

\section{Potential predictors of depressive symptoms}

Bivariate analyses indicated that younger age $(p=0.042)$, number of exposures to conflict-related TEs $(p<0.001)$, higher categorisation of IPV exposure $(\mathrm{p}<0.001)$ and reporting severe family poverty $(\mathrm{p}=0.003)$ were all associated with depressive symptoms at baseline (table 2). At follow-up, younger age $(p=0.040)$, conflict-related TEs $(\mathrm{p}<0.001)$, past-year IPV $(\mathrm{p}<0.001)$ and poverty $(p<0.001)$ were likewise associated with depressive symptoms. In addition, reported physical health symptoms at follow-up in both the woman $(p=0.003)$ and the index child $(\mathrm{p}<0.001)$ were significantly associated with depressive symptoms (table 2 ).

\section{Correlates of functional impairment at follow-up}

Correlates of functional impairment were follow-up indices of depressive symptoms $(\mathrm{r}=0.69 ; \mathrm{p}<0.001)$, IPV $(\mathrm{r}=0.10 ; \mathrm{p}<0.001)$, poverty $(\mathrm{r}=0.15 ; \mathrm{p}<0.001)$ and physical health symptoms in the women $(r=0.19 ; \mathrm{p}<0.001)$. In addition, lifetime TEs measured at baseline were also associated with functional impairment at follow-up $(\mathrm{r}=0.09 ; \mathrm{p}<0.001)$.

\section{Path analysis}

Figure 2 displays the path diagram with standardised estimates $(\beta)$ indicating significant associations. The model demonstrated a good fit to the data $\left(\chi^{2}=23.92, \mathrm{df}=24\right.$, $\mathrm{p}=0.46 ; \mathrm{CFI}=1.00, \mathrm{TLI}=1.00, \mathrm{RMSEA}=0.00, \mathrm{SRMR}=0.014$ ).

\section{Depressive symptoms and functional impairment}

The path diagram indicates that baseline depressive symptoms were associated with follow-up depressive symptoms $(\beta=0.20 ; p<0.001)$, and follow-up depressive symptoms were associated with functional impairment $(\beta=0.35 ; \mathrm{p}<0.001)$.

\section{Indices associated with depressive symptoms}

Trauma-related indices showed the strongest associations with baseline depressive symptoms (conflict-related TEs: $\beta=0.23, p<0.001$; IPV: $\beta=0.26 ; p<0.001)$; other associations included younger age $(\beta=-0.06, p=0.016)$ and poverty $(\beta=0.10, p<0.001)$ (table 3 and figure 2$)$.

The pattern of associations was replicated at follow-up. Indices at follow-up associated with depressive symptoms included IPV $(\beta=0.14 ; p<0.001)$, poverty $(\beta=0.14$; $\mathrm{p}<0.001)$ and health symptoms reported in the child ( $\beta=0.08 ; p=0.001$ ) (figure 2). In addition, TEs measured at baseline were associated with depressive symptoms at follow-up ( $\beta=0.07, p=0.007)$. As indicated, the strongest association with follow-up depressive symptoms were baseline depressive symptoms $(\beta=0.20 ; p<0.001)$, followed by follow-up IPV $(\beta=0.14 ; p<0.001)$ and follow-up poverty $(\beta=0.14 ; \mathrm{p}<0.001)$ (table 3 and figure 2$)$. 
Table 1 Socio-demographic and trauma-related factors, other risk factors and mental health measures at baseline and follow-up

\begin{tabular}{|c|c|c|c|c|c|}
\hline \multirow{2}{*}{$\begin{array}{l}\text { Socio-demographic } \\
\text { characteristics and mental health } \\
\text { indices }\end{array}$} & \multicolumn{2}{|c|}{ Baseline survey $(n=1292)$} & \multicolumn{2}{|c|}{ Follow-up survey $(\mathrm{n}=1292)$} & \multirow[b]{2}{*}{$\begin{array}{l}\text { Baseline vs } \\
\text { follow-up: } p \text { values }\end{array}$} \\
\hline & $\begin{array}{l}\text { Number of } \\
\text { women }\end{array}$ & Col \% & $\begin{array}{l}\text { Number of } \\
\text { women }\end{array}$ & Col \% & \\
\hline Age group (in years) & & & & & $\mathrm{p}<0.001$ \\
\hline$<25$ years & 509 & 39.4 & 314 & 24.3 & \\
\hline $25-29$ & 466 & 36.1 & 482 & 37.3 & \\
\hline$\geq 30$ & 317 & 24.5 & 496 & 38.4 & \\
\hline Mean age (SD) & $26.3(5.1)$ & & $28.4(5.3)$ & & $\mathrm{p}<0.001$ \\
\hline Educational status & & & & & $p=0.053$ \\
\hline None or primary school & 194 & 15.0 & 209 & 16.2 & \\
\hline Junior/senior high school & 761 & 58.9 & 763 & 59.1 & \\
\hline Technical college/diploma & 86 & 6.7 & 77 & 6.0 & \\
\hline University & 251 & 19.4 & 243 & 18.8 & \\
\hline Employment status & & & & & $p=0.218$ \\
\hline Unemployed & 849 & 65.7 & 872 & 67.5 & \\
\hline $\begin{array}{l}\text { Paid employment/small trade/ } \\
\text { farming }\end{array}$ & 443 & 34.3 & 420 & 32.5 & \\
\hline Ongoing financial stressors: Yes ${ }^{\star}$ & 100 & 7.7 & 83 & 6.4 & $\mathrm{p}=0.498$ \\
\hline $\begin{array}{l}\text { Maternal ill health during } \\
\text { pregnancy (follow-up): Yes } \dagger\end{array}$ & & & 136 & 10.5 & \\
\hline Child ill health (follow-up): Yesł & & & 193 & 14.9 & \\
\hline $\begin{array}{l}\text { Conflict-related traumatic events } \\
\text { count: mean (SD)§ }\end{array}$ & & $5.4(3.4)$ & & $3.7(2.4)$ & $p<0.001$ \\
\hline IPVף & & & & & $\mathrm{p}<0.001$ \\
\hline No IPV or low respect/regard & 584 & 45.2 & 499 & 38.6 & \\
\hline Severe psychological abuse & 386 & 29.9 & 295 & 22.8 & \\
\hline Physical abuse & 322 & 24.9 & 498 & 38.6 & \\
\hline PTS: threshold $\geq 2.0$ & 72 & 5.6 & 42 & 3.3 & $p=0.004$ \\
\hline EDS: threshold $\geq 13.0$ & 249 & 19.3 & 163 & 12.6 & $p=0.003$ \\
\hline Total EDS mean score (SD) & & $8.5(4.4)$ & & $6.4(4.8)$ & $\mathrm{p}<0.001$ \\
\hline Total WHODAS mean score (SD) & & $20.3(4.7)$ & & $16.2(4.1)$ & $\mathrm{p}<0.001$ \\
\hline
\end{tabular}

*Score for ongoing financial stressors was generated by adding six items, each of them scored ' 0 ' for 'no economic hardship at all' and ' 1 ' for 'any economic hardship'. Total score was then dichotomised by assigning ' 0 ' for 'no economic hardship at all' and ' 1 ' for 'any economic hardship'.

†Maternal ill health or physical symptoms during pregnancy at follow-up based on endorsing at least one of the listed items: bleeding, severe headache, blurred vision, convulsions, swollen hands/face, high fever, loss of consciousness, difficulty in breathing, severe weakness, severe abdominal pain, accelerated/reduced fetal movement ( $0=$ no physical symptoms; $1=$ one or more physical symptoms).

$\neq$ Child ill health or physical symptoms at follow-up: child suffered from any of the listed causes of sickness $(\mathrm{No}=0$; Yes=1);

$\S$ Total conflict-related traumatic events count at baseline based on the addition of each endorsed trauma item (scored 1).

ףIPV items are grouped as follows. Low respect/regard only: Examples of low respect/regard include extent to which man spends his free time with partner, consults on different household matters, shows respect, trusts partner with money, etc. Severe psychological abuse involves items in which there is threatening, intimidating and controlling behaviour such as jealousy or anger if partner talks to other men, accusations of infidelity, restrictions on meeting friends, limiting contact with family, insisting on knowing partner's whereabouts and humiliating or threatening behaviour. Physical violence included pushing, shaking, throwing objects at partner, slapping, twisting arm, punching, kicking, dragging, strangling, burning, threatening or attacking with weapon or instrument. The typology is hierarchical, that is, the more severe categories can include characteristics in those of a lower order but not vice versa.

EDS, Edinburgh Depression Scale; IPV, Intimate partner violence; PTS, Post-traumatic stress; WHODAS, WHO Disability Assessment Schedule.

Pathways to functional impairment

Follow-up depressive symptoms were most strongly associated with functional impairment $(\beta=0.35 ; \mathrm{p}<0.001)$, followed by maternal physical health symptoms $(\beta=0.14$; $\mathrm{p}<0.001)$ and poverty $(\beta=0.07 ; \mathrm{p}=0.009)$. Indirect pathways to functional impairment included baseline TEs (indirect standardised coefficient $=0.08 ; \mathrm{p}<0.001$ ) and follow-up IPV (indirect standardised coefficient $=0.05 ; \mathrm{p}<0.001$ ). 
Table 2 Associations of candidate variables (to be entered into path analysis) with EDS above threshold score at baseline and follow-up survey

\begin{tabular}{|c|c|c|c|c|c|c|}
\hline \multirow[b]{3}{*}{ Candidate predictor variables } & \multicolumn{3}{|c|}{ Baseline survey } & \multicolumn{3}{|c|}{ Follow-up survey } \\
\hline & \multirow[b]{2}{*}{ Total number } & \multicolumn{2}{|c|}{$\begin{array}{l}\text { Satisfied EDS threshold } \\
\geq 13.0\end{array}$} & \multirow[b]{2}{*}{ Total number } & \multicolumn{2}{|c|}{$\begin{array}{l}\text { Satisfied EDS threshold } \\
\geq 13.0\end{array}$} \\
\hline & & Number & Row \% & & Number & Row \% \\
\hline All women & 1292 & 249 & 19.3 & 1292 & 163 & 12.6 \\
\hline \multicolumn{7}{|l|}{ Age } \\
\hline$<25$ years & 509 & 109 & 21.4 & 314 & 46 & 14.6 \\
\hline $25-29$ & 466 & 94 & 20.2 & 482 & 69 & 14.3 \\
\hline$\geq 30$ years & 317 & 46 & 14.5 & 496 & 48 & 9.7 \\
\hline$\chi^{2}$ test: $p$ values & & & $\mathrm{p}=0.042$ & & & $p=0.042$ \\
\hline \multicolumn{7}{|l|}{ IPV } \\
\hline No or low & 584 & 69 & 11.8 & 499 & 30 & 6.0 \\
\hline Severe psychological abuse alone & 386 & 71 & 18.4 & 295 & 35 & 11.9 \\
\hline Physical and severe psychological abuse & 322 & 109 & 33.9 & 498 & 98 & 19.7 \\
\hline$\chi^{2}$ test: $p$ values & & & $p<0.001$ & & & $p<0.001$ \\
\hline \multicolumn{7}{|l|}{ Poverty index ${ }^{*}$} \\
\hline No poverty/social disadvantage & 322 & 45 & 14 & 311 & 20 & 6.4 \\
\hline Moderate poverty/social disadvantage & 885 & 179 & 20.2 & 907 & 114 & 12.6 \\
\hline Severe poverty/social disadvantage & 85 & 25 & 29.4 & 74 & 29 & 39.2 \\
\hline$\chi^{2}$ test: $p$ values & & & $\mathrm{p}=0.003$ & & & $\mathrm{p}<0.001$ \\
\hline \multicolumn{7}{|l|}{ Maternal ill health (follow-up) } \\
\hline No physical symptoms & & & & 1156 & 135 & 11.7 \\
\hline One or more physical symptoms & & & & 136 & 28 & 20.6 \\
\hline$\chi^{2}$ test: $p$ values & & & & & & $p=0.003$ \\
\hline \multicolumn{7}{|l|}{ Child ill health (follow-up) } \\
\hline No symptoms & & & & 1099 & 122 & 11.1 \\
\hline Presence of symptoms & & & & 193 & 41 & 21.2 \\
\hline$\chi^{2}$ test: $p$ values & & & & & & $\mathrm{p}<0.001$ \\
\hline \multicolumn{7}{|l|}{ EDS at baseline } \\
\hline EDS: threshold $<13.0$ & 1043 & NA & & & 105 & 10.1 \\
\hline EDS: threshold $\geq 13.0$ & 249 & & & & 58 & 22.3 \\
\hline$\chi^{2}$ test: $p$ values & & & & & & $p<0.001$ \\
\hline \multicolumn{7}{|l|}{ Mean TEs at baseline } \\
\hline EDS: threshold <13.0 (mean, SD) & 1043 & & $5.1(3.2)$ & & & $5.2(3.3)$ \\
\hline EDS: threshold $\geq 13.0$ (mean, SD) & 249 & & $6.6(3.5)$ & & & $6.3(3.9)$ \\
\hline t-test: $p$ values & & & $\mathrm{p}<0.001$ & & & $\mathrm{p}<0.001$ \\
\hline
\end{tabular}

*Poverty index at baseline/follow-up based on items inquiring into education (none to high-school level=1; technical/university level=0), employment (unemployed=1; employed $=0$ ) and ongoing economic hardship (no economic hardship=0; any economic hardship=1), scored 0-3 (0=no poverty; $1=$ =moderate poverty; $2,3=$ severe poverty), a higher score representing greater ongoing economic hardship. Economic hardship score generated by adding six items related to ongoing financial stressors, each of them scored '0' for 'no economic hardship at all' and ' 1 ' for 'any economic hardship'. Total score was then dichotomised by assigning of ' 0 ' for 'no economic hardship at all' and ' 1 ' for 'any economic hardship'.

EDS, Edinburgh Depression Scale; IPV, intimate partner violence; NA, not applicable; TE, traumatic effect.

\section{Associations among predictor indices \\ Age}

Younger women recorded higher rates of depressive symptoms $(\beta=-0.06 ; \mathrm{p}=0.016)$, and physical IPV at both baseline $(\beta=-0.13 ; p<0.001)$ and follow-up $(\beta=-0.08$; $\mathrm{p}=0.003)$. Older women reported higher levels of exposure to TEs $(\beta=0.10 ; p=0.001)$, consistent with the duration of time since past mass conflict. 


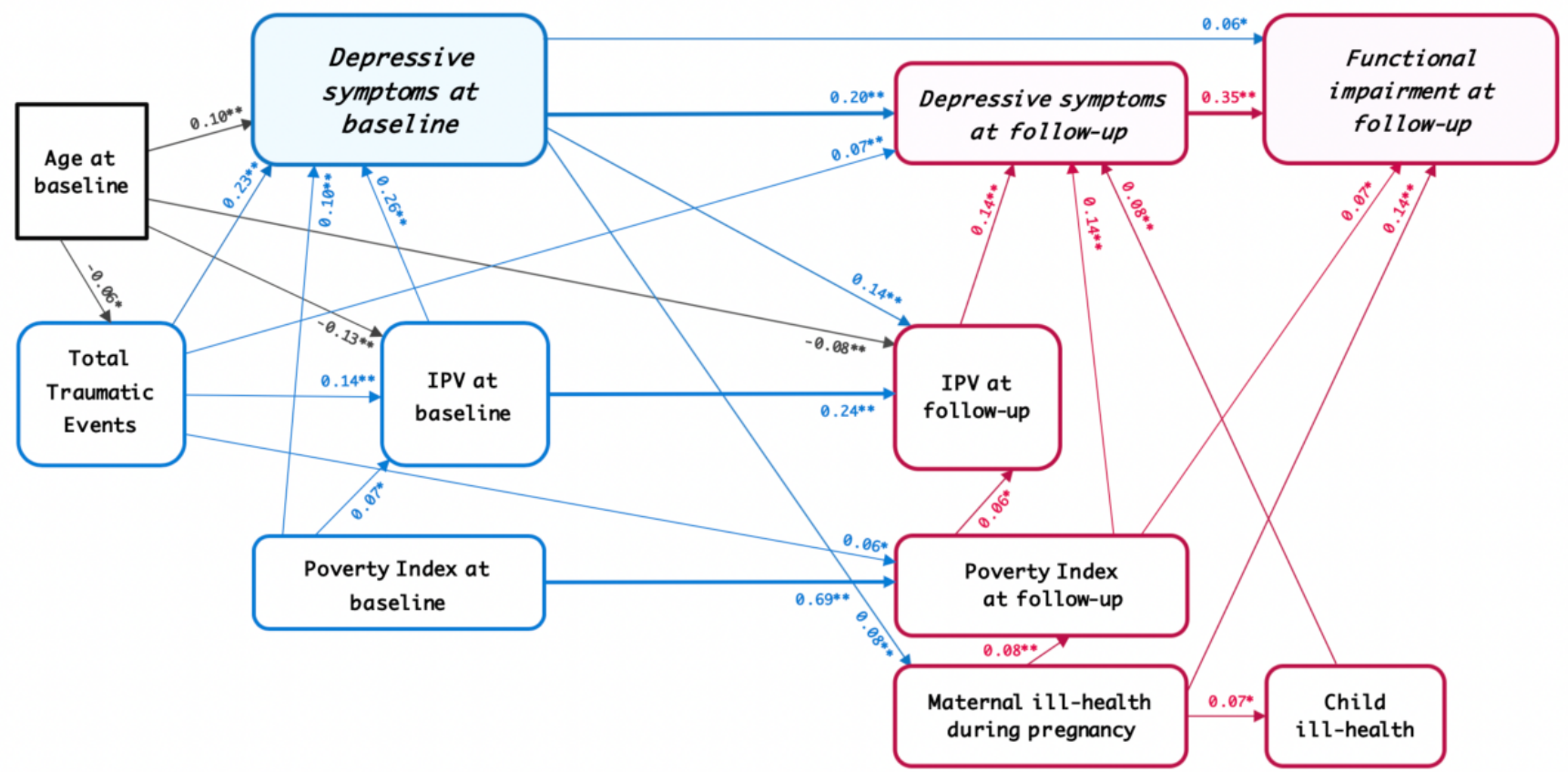

Notes:

Depressive symptoms at baseline/follow-up: EPDS (Total score continuous); Functional impairment: Total added score of 12 items in WHODAS; Age at baseline (categorical 0-4); Total traumatic events count at baseline; Poverty Index at baseline/follow-up: Computed based on education, employment, and ongoing economic problems (0-3; the highest score represents the worst ongoing economic hardship); Maternal ill-health or physical symptoms during pregnancy at follow-up: Experienced any physical symptoms $(\mathrm{No}=0$, Yes=1); Child illhealth or physical symptoms at follow-up: Any symptoms suffered? $(\mathrm{No}=0$, Yes $=1$; symptoms included during late pregnancy period, sickness at birth, and learning/speaking or walking difficulties after birth; general fever and coughing excluded); IPV at baseline/follow-up

"Path analysis applied in structural equation modelling (SEM) framework (all included variables are based on observed data; no latent variables are used in this analysis).

${ }^{*}$ Coefficients are significant at $\mathrm{p}<0.05 ;{ }^{*}$ significant at $\mathrm{p}<0.01$. Only significant direct paths are included in the path diagram.

Box shape: Age is an exogenous variable based on a single item (indicated in square). All other indicators are constructed based on two or more observed measures; represented by boxes with rounded corners. Indicators within blue boxes represent baseline data; indicators within red boxes represent follow-up data. Blue lines connect paths from baseline data while magenta lines connect from follow-up data. Black lines connect endogenous variables to age. Shaded boxes indicate primary outcome variables.

Model summary: CFI (Comparative Fit Index): 1.00; TLI (Tucker-Lewis Index): 1.00;

SRMR (Standardized Root Mean Square Residual): 0.014; RMSEA (90\% CI of RMSEA): 0. 000 (0.00-0.022).

Chi-square Test of Model Fit: Value 23.92; df: 24; $\mathrm{p}=0 \cdot 466$

To minimize the complexity of the path diagram, the following significant indirect paths are not shown. Specific significant indirect paths with standardized coefficients $(\beta)$ :

Total Traum atic Events $\rightarrow$ IPV at follow-up $(\beta=0 \cdot 07, p<0 \cdot 001$, total indirect);

Total Traumatic Events $\rightarrow$ IPV at baseline $\rightarrow$ IPV at follow-up $(\beta=0.03, p<0.001)$;

Total Traumatic Events $\rightarrow$ Depressive symptoms at follow-up $\rightarrow$ IPV at follow-up $(\beta=0.03, p<0.001)$;

Total Traumatic Events $\rightarrow$ Functional impairm ent at follow-up $(\beta=0.08, \mathrm{p}<0 \cdot 001$, total indirect);

Total Traumatic Events $\rightarrow$ Depressive symptoms at follow-up $\rightarrow$ Functional impairment at follow-up $(\beta=0 \cdot 03, p<0 \cdot 01)$;

Total Traumatic Events $\rightarrow$ Depressive symptoms at baseline $\rightarrow$ Functional impairment at follow-up $(\beta=0 \cdot 01, \mathrm{p}<0 \cdot 05)$;

Total Traumatic Events $\rightarrow$ Depressive symptoms at baseline $\rightarrow$ Depressive symptoms at follow-up $\rightarrow$ Functional impairm ent at follow-up $(\beta=0 \cdot 02, \mathrm{p}<0 \cdot 01)$

IPV at baseline $\rightarrow$ Depressive symptoms at baseline $\rightarrow$ Functional impairment at follow-up $(\beta=0.02, p=0 \cdot 027)$;

IPV at baseline $\rightarrow$ Depressive symptoms at baseline $\rightarrow$ Depressive symptoms at follow-up $\rightarrow$ Functional impairm ent at follow-up $(\beta=0 \cdot 02$, $\mathrm{p}<0.001$ );

IPV at follow-up $\rightarrow$ Depressive symptoms at follow-up $\rightarrow$ Functional impairm ent at follow-up $(\beta=0.05, p<0 \cdot 001)$;

Poverty Index at follow-up $\rightarrow$ Depressive symptoms at follow-up $\rightarrow$ Functional impairment at follow-up $(\beta=0 \cdot 05, p<0 \cdot 001)$;

Depressive symptoms at baseline $\rightarrow$ Depressive symptoms at follow-up $\rightarrow$ Functional impairment at follow-up $(\beta=0.07, p<0.01)$;

Depressive symptoms at baseline $\rightarrow$ Maternal-ill health $\rightarrow$ Functional impairment at follow-up $(\beta=0 \cdot 01, p=0 \cdot 013)$;

Child ill-health $\rightarrow$ Depressive symptoms at follow-up $\rightarrow$ Functional impairment at follow -up $(\beta=0 \cdot 03, p=0 \cdot 002)$.

Figure 2 Path model showing statistically significant direct pathways with standardised coefficients. 
Table 3 Path model: standardised direct and indirect effects of age, poverty, family conflict, total conflict-related trauma events, IPV leading to depressive symptoms and functional impairment, at baseline and follow-up

\begin{tabular}{|c|c|c|c|c|c|c|}
\hline \multirow[b]{2}{*}{ Candidate predictor variables } & \multicolumn{2}{|c|}{$\begin{array}{l}\text { Depressive symptoms at } \\
\text { baseline }\end{array}$} & \multicolumn{2}{|c|}{$\begin{array}{l}\text { Depressive symptoms at } \\
\text { follow-up }\end{array}$} & \multicolumn{2}{|c|}{$\begin{array}{l}\text { Functional impairment at } \\
\text { follow-up }\end{array}$} \\
\hline & Coefficient ( $\beta$ ) & $P$ values & Coefficient ( $\beta$ ) & $P$ values & Coefficient ( $\beta$ ) & P values \\
\hline \multicolumn{7}{|l|}{ Direct significant effects ${ }^{*}$} \\
\hline \multicolumn{7}{|l|}{ Baseline survey } \\
\hline Age at baseline & -0.06 & $p=0.016$ & & & & \\
\hline Poverty index at baseline & 0.10 & $\mathrm{p}<0.001$ & & & & \\
\hline $\begin{array}{l}\text { Total traumatic event counts at } \\
\text { baseline }\end{array}$ & 0.23 & $\mathrm{p}<0.001$ & 0.07 & $p=0.006$ & $(0.08)$ & $\mathrm{p}<0.001$ \\
\hline IPV at baseline & 0.26 & $\mathrm{p}<0.001$ & & & & \\
\hline $\begin{array}{l}\text { Depressive symptoms at baseline (total } \\
\text { score) }\end{array}$ & & & 0.20 & $\mathrm{p}<0.001$ & 0.06 & $p=0.023$ \\
\hline \multicolumn{7}{|l|}{ Follow-up survey } \\
\hline Poverty index & & & 0.14 & $\mathrm{p}<0.001$ & 0.07 & $p=0.009$ \\
\hline IPV & & & 0.14 & $\mathrm{p}<0.001$ & $(0.05)$ & $\mathrm{p}<0.001$ \\
\hline Maternal ill health during pregnancy & & & $(0.03)$ & $\mathrm{p}<0.001$ & 0.14 & $p<0.001$ \\
\hline Child ill health & & & 0.08 & $p=0.001$ & $(0.03)$ & $p=0.002$ \\
\hline $\begin{array}{l}\text { Depressive symptoms at follow-up } \\
\text { (total score) }\end{array}$ & & & NA & & 0.35 & $\mathrm{p}<0.001$ \\
\hline Model summary & \multicolumn{6}{|l|}{ Values } \\
\hline$\chi^{2}$ test of model fit & \multicolumn{6}{|c|}{$23.92 ; d f=24 ; p=0.466$} \\
\hline RMSEA $(90 \% \mathrm{Cl}$ of RMSEA) & \multicolumn{6}{|c|}{$0.000(0.000-0.022)$} \\
\hline $\mathrm{CFI}$ & \multicolumn{6}{|l|}{1.00} \\
\hline TLI & \multicolumn{6}{|l|}{1.00} \\
\hline SRMR & \multicolumn{6}{|l|}{0.014} \\
\hline
\end{tabular}

All the variables included in the analyses are based on observed data. Only significant estimates are included in the table. *Indirect significant effects are presented inside bracket in italics.

CFI, Comparative Fit Index; IPV, intimate partner violence; NA, not applicable; RMSEA, Root mean square error of approximation; SRMR, standardised root mean square residual; TLI, Tucker-Lewis Index.

\section{Conflict-related TEs}

TEs were associated directly with baseline IPV $(\beta=0.14$ : $\mathrm{p}<0.001$ ) and indirectly with follow-up IPV (indirect standardised coefficient $=0.08 ; \mathrm{p}<0.001)$. TEs were also associated with women's physical symptoms $(\beta=0.06$; $\mathrm{p}=0.027$ )

\section{Intimate partner violence}

Baseline IPV was associated with follow-up IPV $(\beta=0.24$; $\mathrm{p}<0.001)$.

\section{Poverty}

Baseline poverty was strongly associated with follow-up poverty $(\beta=0.69 ; \mathrm{p}<0.001)$. In addition, at each time point, poverty was associated with IPV (baseline: $\beta=0.07$; $\mathrm{p}<0.012$, follow-up: $\beta=0.06 ; \mathrm{p}<0.026$ ) (figure 2 ).

Physical symptoms

Poverty was associated with maternal physical symptoms $(\beta=0.08 ; p<0.001)$, and there was an association between maternal physical symptoms and child physical symptoms $(\beta=0.07 ; \mathrm{p}=0.012)$ at follow-up.

\section{DISCUSSION}

Although there was a significant decline in depressive symptoms over time from 1 in 5 to 1 in 8 women, 1 in 20 women showed a pattern of persistence or recurrence of this emotional problem over the 2-year time frame. Importantly, follow-up depressive symptoms were the strongest predictor of functional impairment among women. Exposure to past conflict-related trauma showed a persisting association with depressive symptoms although its influence diminished somewhat over time. Poverty measured at baseline showed a strong tendency to persist over the 2-year period and a consistent association with depression. Similarly, IPV showed a tendency to continue over time and to be associated with women's depressive symptoms. There was a relationship between health issues in the mother and child with the latter index being associated with maternal depression. The path model revealed anticipated relationships among predictor variables, for example poverty was related to IPV and poor maternal health, and exposure to conflictrelated trauma was associated with IPV in the family. ${ }^{31}$ 
The percentage of women meeting threshold for depressive symptoms (19.3\%) was broadly consistent with findings from other low-resource countries. ${ }^{32-34}$ The decline in depression prevalence to $12.6 \%$ over time may reflect a combination of factors including the tendency for natural recovery after the stresses of the perinatal period, ${ }^{35}$ the restoration of peace in the country and the associated passage of time since exposure to the traumas of mass conflict. Nevertheless, one-fifth of women who were depressed at baseline continued to report abovethreshold depressive symptoms at follow-up, consistent with the positive correlation found between symptoms at the two time points. Importantly, depressive symptoms at follow-up were strongly associated with functional impairment. Taken together, trauma-related factors (conflictrelated TEs, IPV) showed important associations with depressive symptoms both directly and via pathways involving other indices. As shown in past studies in other settings, ${ }^{93}$ poverty and poor general health of the woman and infant made additional contributions to both depressive symptoms and functional impairment.

Strengths of this study include the systematic recruitment strategy, longitudinal design, large sample size, high initial response rate and acceptable level of retention of participants at follow-up. The team has a long experience in adapting measures to the culture and context of TimorLeste and in undertaking population-based research in that setting. ${ }^{23}$ The field team received intensive training and extensive supervision, and our team members remained with the project throughout both assessment periods. Although not a diagnostic measure, the EPDS has the advantage of providing a readily replicated index of depressive symptoms at the community level, allowing benchmarking against other international studies. ${ }^{33}$

In relation to limitations, an important constraint inherent to studies of this kind is the issue of collinearity among comorbid measures of mental health symptoms. For that reason, even though symptoms of PTSD are of practical and theoretical interest in this field, the index measuring this domain was excluded because of high levels of collinearity with depressive symptoms, and the latter were the core focus of this study given their strong association with functional impairment. The corollary, however, is that the high correlation between PTSD and depressive symptoms represents an indirect test of validity in assessing the latter construct insofar as the association with PTSD is well-established across the international literature. ${ }^{36}$ Although beyond the scope of this report, future analyses may examine more closely the association of PTSD and depressive symptoms in this sample, following the approaches used in the recent literature.

In designing the study, we elected to use the EPDS as our index of depressive symptoms for several reasons. The measure is the most commonly used in the maternal mental health field and has a strong legacy of testing and cultural and linguistic adaptation across cultures. ${ }^{37}$ The large body of studies using the measure provides a foundation for benchmarking our findings against those of other inquiries conducted in a diversity of settings. Furthermore, the measure is brief and readily applied in a clinic or community setting by lay-field workers with no previous background in mental health. As such, the use of the EPDS in the antenatal clinics offered an opportunity to familiarise these services with the use of the measure as a screen for depressive symptoms. The concomitant limitation, however, is that the EPDS cannot provide a definitive diagnosis of major depressive disorder for either clinical or epidemiological purposes. Above threshold scores can only serve as an indicator that the woman requires a further, more comprehensive clinical assessment to determine need for treatment.

Several inferences can be derived from our findings. Although depressive symptoms have a strong tendency to resolve over 2 years among Timorese women following the birth of a child, a minority of women show a pattern of persistence or recurrence of these problems. Important to the key hypothesis of our study was the finding that depressive symptoms showed the strongest association with functional impairment based on the widely used WHO measure which includes activities in all aspects of life including engagement and activity at a society-wide level. These findings suggest that the presence of depressive symptoms may play a critical role in impairing women to engage in work and society at the age when these activities are most critical to that gender group, thereby limiting their capacity to participate fully in the process of reconstruction and development following periods of mass conflict. These associations therefore should be of central concern to the broader field of postconflict recovery and development given that the achievement of gender equality and the participation of women are high priorities. $^{2}$

The role demonstrated for TEs in the relevant pathways identified indicates the importance of the longer-term effects of mass conflict on mental health and functioning among women in the childbearing and child-rearing age, and the pivotal role that depressive symptoms can play in the sequence leading to adverse social outcomes. Moreover, our findings underscore the maxim that trauma can lead to further trauma, indicated by the association between exposure to past conflict-related trauma-occurring a minimum of 6 years prior to baseline assessment-and levels of IPV occurring in the past year. This pattern provides further evidence to support the thesis that the traumas of conflict can lead to trauma and abuse in the home during the postconflict period, thereby perpetuating or precipitating mental health symptoms (in this instance, of depression) that continue to impact on the capacity of women to function. Although not a focus of the present analysis, there is ample evidence that maternal depression can have multiple adverse impacts on the social and emotional well-being, and psychological development of infants and young children. ${ }^{38}$

It is noted that the prevalence of physical IPV increased over time whereas the impact of this form of abuse on women's mental health showed a corresponding 
reduction. Pregnancy may act as a partial deterrent against IPV but its effects on mental health may be more severe given that the woman is in a state of heightened psychological vulnerability and insecurity being concerned not only for her own physical safety but also about risks of harm to the fetus. ${ }^{39}$

Our findings underscore the need to adopt a comprehensive, multisectoral approach to addressing the issue of depressive symptoms among women in the childbearing age in postconflict countries. Those who screen positive on measures such as the EPDS require more comprehensive assessments for the presence of clinically significant depressive disorders and women with severe depression should be referred to non-stigmatising culturally sensitive community-based services; a model that has been adopted in Timor-Leste over the past 20 years. ${ }^{40}$ In addition, once detected, IPV requires direct attention in view of its grave physical and mental health consequences, and also because the abuse represents a grave human rights violation that undermines the fabric of society and represents a contravention of the law. ${ }^{41}$ In that regard, our findings as a whole have important implications in directing attention towards the family as a major factor determining the onset and course of depressive symptoms among women. In that respect, it is noteworthy that the major risk factors for depressive symptoms and their persistence include the inter-related issues of poverty, domestic violence and poor health of the mother and the infant. ${ }^{42}$ In that sense, women who are depressed act as a sentinel indicator of a family that is likely facing multiple forms of psychosocial adversity. ${ }^{43}$ A comprehensive family-based approach to assessment and intervention therefore warrants close attention in postconflict settings such as Timor-Leste.

\section{CONCLUSIONS}

Our longitudinal path model indicated that depressive symptoms may be major impediment to functioning among women of child-rearing age in postconflict countries such as Timor-Leste. Moreover, exposure to past conflict-related trauma and ongoing IPV-factors that are inter-related-contribute to depressive symptoms. Other forms of deprivation and adversity, such as poverty, and physical ill health contribute to pathways to depression and functional impairment. Greater recognition of the importance of depressive symptoms and their association with trauma and family-related adversity in shaping the capacity of women to function in postconflict societies may enhance the effectiveness of policies, and planning and implementation strategies of recovery and development that prioritise participation of women in these societies. At a political level, preventing recurrent cycles of violence both in society and in the home will be a major step in establishing social stability, reducing mental health problems such as depression among women and promoting gender equality and women's participation in postconflict countries such as Timor-Leste.

\section{Author affiliations}

${ }^{1}$ Psychiatry, University of New South Wales, Sydney, New South Wales, Australia ${ }^{2}$ Mental Health Academic Unit, Liverpool Hospital, Sydney, New South Wales, Australia

${ }^{3}$ Child and Maternal Health, Alola Foundation, Dili, Timor-Leste

${ }^{4}$ Psychology, The University of Sydney, Sydney, New South Wales, Australia ${ }^{5}$ Department of Mental Health, Johns Hopkins Sch Publ Hlth, Baltimore, Maryland, USA

${ }^{6}$ Richmond Hospital, St John of God Health Care, North Richmond, New South Wales, Australia

Contributors DS and SJR designed the study, oversaw all aspects of its implementation including management, training and supervision, ensured the integrity of data collection and interactions with supportive agencies and took a lead in directing data management, analyses and writing of this manuscript; DS, SJR, WAT, ZS, MD and VE formulated the project, wrote the grant and received funding for this project; WAT, MD, VE, MM and ZS provided statistical guidance, feedback and advice; MM, DS and LK were responsible for the actual statistical analysis, design of figures and production of tables; SJR and LK conducted the literature review; NDJT provided cultural advice and oversight, oversaw field work and logistic support and provided on-the-ground supervision of the field team; DS, SJR, MM and LK prepared and revised the written manuscript; ZdC and ES were responsible for assisting with management, logistic and management support, attending to coordination of staff, overseeing and participating in data collection and checking and liaising with the hosting agency, the Alola Foundation and stakeholder groups. DS, SJR, WAT, ZS, MD and VE participated in regular planning meetings ensuring that all aspects of the project were monitored and, where necessary, adjusted to achieve the outcomes. WAT, ZS, MD and VE played an active role in assessing and advising on the methodological, analytical and theoretical interpretation of the data and in designing the structure of the paper. All authors reviewed and provided input into the final manuscript.

Funding Funding for this research was provided by the National Health and Medical Research Council (NHMRC) of Australia.

Competing interests None declared.

Patient and public involvement Patients and/or the public were not involved in the design, or conduct, or reporting, or dissemination plans of this research.

Patient consent for publication Not required.

Ethics approval This study was approved by the Human Research Ethics Committee of the University of New South Wales and the Ministry of Health of Timor-Leste.

Provenance and peer review Not commissioned; externally peer reviewed.

Data availability statement Data are available on request. The data that support the findings of this study are available on request from the corresponding author, SR. However, the data are part of body of research that is ongoing and are therefore neither comprehensive nor complete. The data are not publicly available due to their containing information that could compromise the privacy of research participants.

Open access This is an open access article distributed in accordance with the Creative Commons Attribution Non Commercial (CC BY-NC 4.0) license, which permits others to distribute, remix, adapt, build upon this work non-commercially, and license their derivative works on different terms, provided the original work is properly cited, appropriate credit is given, any changes made indicated, and the use is non-commercial. See: http://creativecommons.org/licenses/by-nc/4.0/.

\section{ORCID iD}

Louis Klein http://orcid.org/0000-0002-0634-0538

\section{REFERENCES}

1 Report on the fifty-eighth session. 15 March 2013 and 10-21 March 2014), E/2014/27-E/CN.6/2014/15. New York: UN Commission on the Status of Women, 2014. https://www.refworld.org/docid/ 5a5f2da84.html

2 García-Moreno C, Amin A. The sustainable development goals, violence and women's and children's health. Bull World Health Organ 2016;94:396-7.

3 Ellsberg M, Jansen HAFM, Heise L, et al. Intimate partner violence and women's physical and mental health in the who multi-country study on women's health and domestic violence: an observational study. The Lancet 2008;371:1165-72. 
4 Beydoun HA, Beydoun MA, Kaufman JS, et al. Intimate partner violence against adult women and its association with major depressive disorder, depressive symptoms and postpartum depression: a systematic review and meta-analysis. Soc Sci Med 2012;75:959-75

5 Herrman H, Kieling C, McGorry P, et al. Reducing the global burden of depression: a Lancet-World psychiatric association Commission. The Lancet 2019;393:e42-3.

6 Nolen-Hoeksema S. Gender differences in depression. Curr Dir Psychol Sci 2001;10:173-6.

7 Woody CA, Ferrari AJ, Siskind DJ, et al. A systematic review and meta-regression of the prevalence and incidence of perinatal depression. J Affect Disord 2017;219:86-92.

8 Gelaye B, Rondon MB, Araya R, et al. Epidemiology of maternal depression, risk factors, and child outcomes in low-income and middle-income countries. Lancet Psychiatry 2016;3:973-82.

9 Hahn-Holbrook J, Cornwell-Hinrichs T, Anaya I. Economic and health predictors of national postpartum depression prevalence: a systematic review, meta-analysis, and meta-regression of 291 studies from 56 countries. Front Psychiatry 2017;8:248.

10 Jewkes R, Fulu E, Roselli T, et al. Prevalence of and factors associated with non-partner rape perpetration: findings from the un Multi-country cross-sectional study on men and violence in Asia and the Pacific. Lancet Glob Health 2013;1:e208-18.

11 Charlson FJ, Flaxman A, Ferrari AJ, et al. Post-Traumatic stress disorder and major depression in conflict-affected populations: an epidemiological model and predictor analysis. Glob Ment Health 2016;3:e4.

12 Steel Z, Chey T, Silove D, et al. Association of torture and other potentially traumatic events with mental health outcomes among populations exposed to mass conflict and displacement: a systematic review and meta-analysis. JAMA 2009;302:537-49.

13 Kessler RC, Aguilar-Gaxiola S, Alonso J, et al. Trauma and PTSD in the who world mental health surveys. Eur J Psychotraumatol 2017;8:1353383.

14 Rees SJ, Tol W, Mohsin M, et al. A high-risk group of pregnant women with elevated levels of conflict-related trauma, intimate partner violence, symptoms of depression and other forms of menta distress in post-conflict Timor-Leste. Trans/ Psychiatry 2016;6:e725.

15 Rees S, Silove D, Chey T, et al. Lifetime prevalence of gender-based violence in women and the relationship with mental disorders and psychosocial function. JAMA 2011;306:513-21.

16 Silove D, Rees S, Tay AK, et al. Pathways to perinatal depressive symptoms after mass conflict in Timor-Leste: a modelling analysis using cross-sectional data. Lancet Psychiatry 2015:2:161-7.

17 Tol WA, Rees SJ, Tay AK, et al. Cohort profile: maternal mental health and child development in situations of past violent conflict and ongoing adversity: the DILI birth cohort study. Int J Epidemiol 2018;47:17-17h.

18 Silove D, Manicavasagar V, Baker K, et al. Indices of social risk among first attenders of an emergency mental health service in post-conflict East Timor: an exploratory investigation. Aust N Z J Psychiatry 2004;38:929-32.

19 Tennant C, Silove D. The development of a mental health service in East Timor: an Australian mental health relief project. Int. psychiatry 2005;2:17-19.

20 van Ommeren M, Sharma B, Thapa S, et al. Preparing instruments for transcultural research: use of the translation monitoring form with Nepali-speaking Bhutanese refugees. Transcult Psychiatry 1999;36:285-301

21 Cox JL, Holden JM, Sagovsky R. Detection of postnatal depression. development of the 10-item Edinburgh postnatal depression scale. Br J Psychiatry 1987;150:782-6.

22 Berthold SM, Mollica RF, Silove D, et al. The HTQ-5: revision of the Harvard trauma questionnaire for measuring torture, trauma and DSM-5 PTSD symptoms in refugee populations. Eur J Public Health 2019:29:468-74.
23 Silove D, Liddell B, Rees S, et al. Effects of recurrent violence on post-traumatic stress disorder and severe distress in conflictaffected Timor-Leste: a 6-year longitudinal study. Lancet Glob Health 2014;2:e293-300.

24 García-Moreno C, Jansen HAFM, Ellsberg M, et al. Prevalence of intimate partner violence: findings from the who multi-country study on women's health and domestic violence. The Lancet 2006;368:1260-9.

25 Üstün TB, Kostanjsek N, Chatterji S, et al. Measuring health and disability: manual for who disability assessment schedule (WHODAS 2.0). Geneva: World Health Organization, 2010.

26 World Health Organization. Maternal mental health and child health and development in low and middle income countries. Geneva: World Health Organization, 2008. http://www.who.int/iris/handle/ $10665 / 43975$

27 JJB H, Bechger TM. An introduction to structural equation modeling. Fam Sci Rev 1998;11:354-73.

28 Marcoulides GAS, Schumacker RE. Advanced structural equation modeling: issues and techniques. New Jersey: Lawrence Erlbaum Associates, 1996.

29 Muthén LK, Muthén BO. Mplus User's Guide. $7^{\text {th }}$ ed. Los Angeles: Muthén \& Muthén, 1998-2012.

30 IBMCorp. Ibm SPSS statistics for windows, version 22.0. New York: IBM Corp, 2013

31 Rees S, Mohsin M, Tay AK, et al. Risk of perpetrating intimate partner violence amongst men exposed to torture in conflict-affected Timor-Leste. Glob Ment Health 2018;5:e23.

32 Friedrich MJ. Depression is the leading cause of disability around the world. JAMA 2017;317:1517.

33 Fisher J, Cabral de Mello M, Patel V, et al. Prevalence and determinants of common perinatal mental disorders in women in low- and lower-middle-income countries: a systematic review. Bull World Health Organ 2012;90:139-49.

34 Kessler RC, Aguilar-Gaxiola S, Alonso J, et al. The global burden of mental disorders: an update from the who world mental health (WMH) surveys. Epidemiol Psichiatr Soc 2009;18:23-33.

35 Sexton MB, Flynn HA, Lancaster $\mathrm{C}$, et al. Predictors of recovery from prenatal depressive symptoms from pregnancy through postpartum. $J$ Womens Health 2012;21:43-9.

36 Momartin S, Silove D, Manicavasagar V, et al. Comorbidity of PTSD and depression: associations with trauma exposure, symptom severity and functional impairment in Bosnian refugees resettled in Australia. J Affect Disord 2004;80:231-8.

37 Shrestha SD, Pradhan R, Tran TD, et al. Reliability and validity of the Edinburgh postnatal depression scale (EPDS) for detecting perinatal common mental disorders (PCMDs) among women in low-and lower-middle-income countries: a systematic review. BMC Pregnancy Childbirth 2016;16:72.

38 Netsi E, Pearson RM, Murray L, et al. Association of persistent and severe postnatal depression with child outcomes. JAMA Psychiatry 2018;75:247-53.

39 Pawlby S, Sharp D, Hay DF. Prevalence of maternal psychiatric disorder in pregnancy: 1986 and 2016. Br J Psychiatry 2019;214:116.

40 Epping-Jordan JE, van Ommeren M, Ashour HN, et al. Beyond the crisis: building back better mental health care in 10 emergencyaffected areas using a longer-term perspective. Int $J$ Ment Health Syst 2015;9:1-10.

41 Silove D. The best immediate therapy for acute stress is social. Bull World Health Organ 2005;83:75-7.

42 Rees S, Thorpe R, Tol W, et al. Testing a cycle of family violence model in conflict-affected, low-income countries: a qualitative study from Timor-Leste. Soc Sci Med 2015;130:284-91.

43 Silove DM, Tay AK, Steel Z, et al. Symptoms of post-traumatic stress disorder, severe psychological distress, explosive anger and grief amongst partners of survivors of high levels of trauma in postconflict Timor-Leste. Psychol Med 2017;47:149-59. 